\title{
Pulmonary vasodilators can lead to various complications in pulmonary "arterial" hypertension associated with congenital heart disease
}

\author{
Ayako Chida-Nagai ${ }^{1} \cdot$ Koichi Sagawa $^{2} \cdot$ Takao Tsujioka $^{1} \cdot$ Takanori Fujimoto $^{1} \cdot$ Kota Taniguchi $^{1} \cdot$ Osamu Sasaki $^{1}$. \\ Gaku Izumi $^{1} \cdot$ Hirokuni Yamazawa $^{1} \cdot$ Naoki Masaki $^{3} \cdot$ Atsushi Manabe $^{1} \cdot$ Atsuhito Takeda $^{1}$
}

Received: 20 December 2019 / Accepted: 3 April 2020 / Published online: 13 April 2020

(c) Springer Japan KK, part of Springer Nature 2020

\begin{abstract}
Congenital heart disease-associated pulmonary arterial hypertension (CHD-PAH) is one of the major complications in patients with CHD. A timely closure of the left-to-right shunt will generally result in the normalization of the pulmonary hemodynamics, but a few patients have severe prognosis in their early childhood. We hypothesized that wide-ranging pathological mechanism in PAH could elucidate the clinical state of severe CHD-PAH. Using electronic medical records, we retrospectively analyzed six infants with severe CHD-PAH who had treatment-resistant PH. All patients were born with congenital malformation syndrome. After starting on a pulmonary vasodilator, five of the six patients developed complications including pulmonary edema and interstitial lung disease (ILD), and four patients had alveolar hemorrhage. After steroid therapy, the clinical condition improved in four patients, but two patients died. The autopsy findings in one of the deceased patients indicated the presence of recurrent alveolar hemorrhage, pulmonary venous hypertension, ILD, and PAH. Based on the clinical course of these CHD-PAH in patients and the literature, CHD-PAH can occur with pulmonary vascular obstructive disease (PVOD)/pulmonary capillary hemangiomatosis (PCH), ILD, and/or alveolar hemorrhage. The severity of CHD-PAH may depend on a genetic disorder, respiratory infection, and upper airway stenosis. Additionally, pulmonary vasodilators may be involved in the development of PVOD/PCH and ILD. When patients with CHD-PAH show unexpected deterioration, clinicians should consider complications associated with PVOD/PCH and/or pulmonary disease. In addition, the choice of upfront combination therapy for pediatric patients with CHD-PAH should be selected carefully.
\end{abstract}

Keywords Congenital heart disease-associated pulmonary arterial hypertension · Pulmonary veno-occlusive disease/ pulmonary capillary hemangiomatosis $\cdot$ Interstitial lung disease $\cdot$ Alveolar hemorrhage

\section{Introduction}

Pulmonary arterial hypertension (PAH) is a severe, progressive disorder characterized by a high pulmonary arterial pressure [1]. Pulmonary veno-occlusive disease (PVOD)/ pulmonary capillary hemangiomatosis $(\mathrm{PCH})$ is a rare type

Atsuhito Takeda

a-takeda@med.hokudai.ac.jp

1 Department of Pediatrics, Hokkaido University, Kita14, Nishi5, Kita-Ku, Sapporo, Hokkaido 060-8648, Japan

2 Department of Pediatric Cardiology, Fukuoka Children's Hospital, Fukuoka, Japan

3 Division of Cardiovascular Surgery, Tohoku University Graduate School of Medicine, Sendai, Japan of pulmonary hypertension ( $\mathrm{PH})$ defined by increased pulmonary vascular resistance caused by capillary or postcapillary disorder [2, 3]. PAH and PVOD/PCH can overlap pathologically and genetically $[4,5]$. In addition, $\mathrm{PVOD} / \mathrm{PCH}$ was reclassified as "PAH with overt features of venous/capillary (PVOD/PCH) involvement" in the latest World Symposium on Pulmonary Hypertension (WSPH) in 2018 [6]. The revised classification reveals that $\mathrm{PAH}$ has a more extensive clinical course than previously anticipated. We describe six pediatric patients with severe, treatment-resistant, congenital heart disease-associated PAH (CHD-PAH), and analyze their clinical conditions based on the WSPH statement and previous literature. We hypothesized that a wide-ranging pathological mechanism in PAH could elucidate the clinical state of severe CHD-PAH. 


\section{Patients and methods}

Based on the electronic medical records, we retrospectively reviewed CHD-PAH patients whose systolic pulmonary arterial pressure was estimated to be equal to or higher than systemic systolic blood pressure and in whom specific pulmonary vasodilator was not effective, in Hokkaido University Hospital and Fukuoka Children's Hospital from January 2008 to December 2018.

The Institutional Review Board (IRB) of Hokkaido University Hospital for clinical research approved this study (IRB approval no. 019-0003). The IRB of Fukuoka Children's Hospital for clinical research also approved the study (IRB approval no. 2019-13). Information regarding the present study was disclosed on Hokkaido University website for an opt out of approval, because three of the patients died. Informed consent for the living patients was waived due to the retrospective nature of the study.

\section{Illustrative cases}

Six infants were included in this analysis. Four patients were born with trisomy 21 , one with trisomy 18 , and one with VACTERL association (the last patient had cardiac malformation, anal atresia, and limb anomaly) (Table 1). The median age (range) at $\mathrm{PH}$ progression was 5 months (3 months to 1 year and 4 months). As shown in Table 2, all the patients had an estimated systolic pulmonary arterial pressure that was equal to or higher than the systemic systolic blood pressure. Before PH progression, patient 3 had a mycoplasma infection, and patient 6 developed respiratory syncytial virus infection. All patients were diagnosed as having CHD-PAH progression, and a variety of pulmonary vasodilators were used (Table 3 ). After initiation of this treatment, patients developed alveolar hemorrhage, interstitial lung disease (ILD), acute respiratory distress syndrome, and so on. The median value (range) of the maximum serum
KL-6 level was 2219 (1987-6273) U/mL (reference range $<400 \mathrm{U} / \mathrm{mL}$ ). Clinical condition of four of the patients improved, while the remaining two patients died, and the cause of death was related to CHD-PAH. Here, we describe the detailed clinical courses of CHD-PAH in patient 2 and patient 3 as representative patients.

\section{Patient 2}

A girl was born at 38 weeks of gestation with a birth weight of $3.0 \mathrm{~kg}$. At 1-month-old medical checkup, she had poor weight gain, poor feeding, and a specific appearance suggestive of trisomy 21 . The chromosomal examination confirmed trisomy 21 . She was referred to the pediatric cardiology outpatient clinic, and was diagnosed with complete atrioventricular septal defect, patent ductus arteriosus (PDA), and PH. Cardiac catheterization was performed at 56 days of age; her left-ventricular pressure (systolic/end-diastolic) was $51 / 8 \mathrm{mmHg}$, right-ventricular pressure (systolic/end-diastolic) was $53 / 7 \mathrm{mmHg}$, main pulmonary arterial pressure (systolic/diastolic/mean) was 49/14/31 mmHg, pulmonary-to-systemic flow ratio was 1.91 , and pulmonary vascular resistance was 4.81 Wood units $\cdot \mathrm{m}^{2}$. At 64 days of age, intracardiac repair and PDA ligation were performed. Postoperatively, her right-ventricular pressure estimated by ultrasonic echocardiography was still very high and almost equal to the left-ventricular pressure. She required nitric oxide (NO) inhalation even after endotracheal extubation at 77 days of age. At 95 days of age, NO inhalation was stopped and she had a cough and labored breathing. Decreasing the amount of milk feeding and increasing the dose of diuretics improved her respiration only temporarily. Her chest $\mathrm{X}$-ray showed interstitial markings, so intravenous prednisolone was started at 110 days of age, and her respiratory status dramatically improved. We switched intravenous prednisolone to oral prednisolone on the next day. However, we suspected that severe PAH still remained, so at 113 days of age, oral bosentan was started. At 120 days of

Table 1 Characteristics of all patients

\begin{tabular}{lllll}
\hline $\begin{array}{l}\text { Patient num- } \\
\text { ber }\end{array}$ & Sex & Genetic disorder & Complication of CHD & Former surgical procedure (age at operation) \\
\hline 1 & Female & Trisomy 21 & PA, VSD & ICR $(4 \mathrm{~m})$ \\
2 & Female & Trisomy 21 & cAVSD, PDA & ICR $(2 \mathrm{~m})$ \\
3 & Male & Trisomy 21 & VSD, AP window & AP window repair $(6 \mathrm{~d})$ \\
4 & Male & Trisomy 21 & cAVSD, PDA, ASD type II & PAB and PDA ligation $(2 \mathrm{~d})$, ICR $(5 \mathrm{~m})$ \\
5 & Female & Trisomy 18 & VSD, ASD, PDA, DCRV & PAB and PDA ligation $(7 \mathrm{~m})$ \\
6 & Male & VACTERL association & VSD, PAPVC & None \\
\hline
\end{tabular}

$C H D$ congenital heart disease, $P A$ pulmonary atresia, $V S D$ ventricular septal defect, $I C R$ intracardiac repair, $c A V S D$ complete atrioventricular septal defect, $P D A$ patent ductus arteriosus, $A P$ window aortopulmonary window, $A S D$ atrial septal defect, $D C R V$ double-chambered right ventricle, $P A B$ pulmonary artery banding, $P A P V C$ partial anomalous pulmonary venous connection 
Table 2 Hemodynamic parameters in patients

\begin{tabular}{|c|c|c|c|c|c|c|c|c|c|}
\hline $\begin{array}{l}\text { Patient } \\
\text { number }\end{array}$ & Measurement period & $\begin{array}{l}\text { PAP: systolic/ } \\
\text { diastolic/mean } \\
(\mathrm{mmHg})\end{array}$ & $\begin{array}{l}\text { mRAP } \\
(\mathrm{mmHg})\end{array}$ & $\mathrm{CI}\left(\mathrm{L} / \mathrm{min} / \mathrm{m}^{2}\right)$ & $\begin{array}{l}\text { PVR } \\
\text { (wood } \\
\text { units } / \mathrm{m}^{2} \text { ) }\end{array}$ & $\begin{array}{l}\text { mPAWP } \\
(\mathrm{mmHg})\end{array}$ & $\begin{array}{l}\text { Systolic } \\
\text { systemic BP } \\
(\mathrm{mmHg})\end{array}$ & Qp/Qs & $\begin{array}{l}\text { eRVSP } \\
(\mathrm{mmHg})\end{array}$ \\
\hline \multirow[t]{2}{*}{1} & Before ICR & - & 2 & 5.47 & 3.4 & - & 74 & 2.31 & - \\
\hline & $\begin{array}{l}\text { After ICR and PH } \\
\text { progression }^{\mathrm{a}}\end{array}$ & $45 / 14 / 29$ & 3 & 4.2 & 5.76 & 7 & 89 & 1.03 & $-^{\mathrm{b}}$ \\
\hline \multirow[t]{2}{*}{2} & Before ICR & $49 / 14 / 31$ & - & - & 4.81 & - & 51 & 1.91 & - \\
\hline & $\begin{array}{l}\text { After ICR and PH progres- } \\
\text { sion }\end{array}$ & - & - & - & - & - & - & - & 75 \\
\hline \multirow[t]{2}{*}{3} & Before vasodilator induction & - & - & - & - & - & - & - & $-^{\mathrm{b}}$ \\
\hline & After vasodilator induction & - & - & - & - & - & - & - & $-{ }^{\mathrm{b}}$ \\
\hline \multirow[t]{2}{*}{4} & Before $\mathrm{pH}$ progression & - & - & - & - & - & - & - & $-^{\mathrm{b}}$ \\
\hline & After $\mathrm{PH}$ progression ${ }^{\mathrm{c}}$ & $65 / 36 / 50$ & - & - & - & $7^{\mathrm{d}}$ & 69 & 2.4 & $-^{\mathrm{b}}$ \\
\hline \multirow[t]{2}{*}{5} & Before vasodilator induction & - & - & - & - & - & - & - & $-^{\mathrm{b}}$ \\
\hline & After vasodilator induction & - & - & - & - & - & - & - & $-^{\mathrm{b}}$ \\
\hline \multirow[t]{2}{*}{6} & Before $\mathrm{PH}$ progression & - & - & - & - & - & - & - & $-^{\mathrm{e}}$ \\
\hline & After PH progression & - & - & - & - & - & - & - & $-{ }^{\mathrm{f}}$ \\
\hline
\end{tabular}

-, not available, $m P A P$ mean pulmonary arterial pressure, $R A P$ right atrial pressure, $C I$ cardiac index, $P V R$ pulmonary vascular resistance, $m P A W P$ mean pulmonary artery wedge pressure, $B P$ blood pressure, $Q p / Q s$ pulmonary blood flow-to-systemic blood flow ratio, $e R V S P$ estimated right-ventricular systolic pressure, $I C R$ intracardiac repair, $P H$ pulmonary hypertension

${ }^{a}$ The catheterization was performed with $10 \mathrm{~L} / \mathrm{min}$ oxygen and nitric oxide $5 \mathrm{ppm}$ inhalation

${ }^{\mathrm{b}}$ The pressure in the RV was estimated to be almost equal to that of the LV by interventricular septum shape

${ }^{\mathrm{c}}$ The catheterization was performed with intubated state (fraction of inspiratory oxygen 0.4 )

${ }^{\mathrm{d}}$ The mean pulmonary vein pressure is displayed

${ }^{\mathrm{e}} \mathrm{A}$ left-to-right shunt flow in ventricular septal defect was detected

${ }^{\mathrm{f}} \mathrm{A}$ right-to-left shunt flow in ventricular septal defect was detected

age, prominent labored breathing and hypoxemia started. Intravenous dexamethasone improved her condition temporally, but labored breathing and hypoxemia remained. At 139 days of age, she developed acute bronchitis and underwent endotracheal intubation. Intravenous dexamethasone and ampicillin improved her condition temporally. Her chest high-resolution computed tomography (HRCT) showed panlobular ground-glass opacity and interlobular septal thickening (Fig. 1). At 176 days of age, her respiratory status deteriorated further, so we started methylprednisolone pulse therapy in the intensive-care unit. Subsequently, she developed alveolar hemorrhage and hypovolemic shock and died at 181 days of age.

A lung autopsy was performed after obtaining informed consent from her parents. Histopathological findings showed narrowing and obstructive small pulmonary arteries with medial thickening, hemosiderin deposition, lymphangiectasia, many emphysematous bullae, fibrous thickening of the cell walls, and intimal fibrous thickening of almost $50 \%$ of the pulmonary veins (Fig. 2a-d). These findings indicated the presence of recurrent alveolar hemorrhage, pulmonary venous hypertension, ILD, and $\mathrm{PAH}$.

\section{Patient 3}

A boy was suspected of having CHD in his fetal stage. He was born at 36 weeks of gestation with a birth weight of $2.8 \mathrm{~kg}$. Just after birth, he was diagnosed as having ventricular septal defect (VSD) and aortopulmonary window (AP window). At 6 days of age, he underwent AP window repair. At that time, we did not perform VSD closure or pulmonary artery banding (PAB) because the main pulmonary artery was hypoplastic and seemed to restrict pulmonary arterial flow. The chromosomal examination revealed that he had trisomy 21 . He was discharged at 76 days of age. However, during regular visits, the ultrasound cardiogram revealed reduction in pulmonary artery flow velocity, and progression of PH was suspected. Therefore, at 156 days of age, oral bosentan and home oxygen therapy were started. Bosentan was switched to macitentan at 160 days of age. Subsequently, he developed cyanosis and respiratory failure, and was admitted to the hospital as an emergency at 166 days of age. He required tracheal intubation and ventilator management, which temporarily improved his respiratory status. We considered $\mathrm{PH}$ crisis followed by an upper airway obstruction, so we 


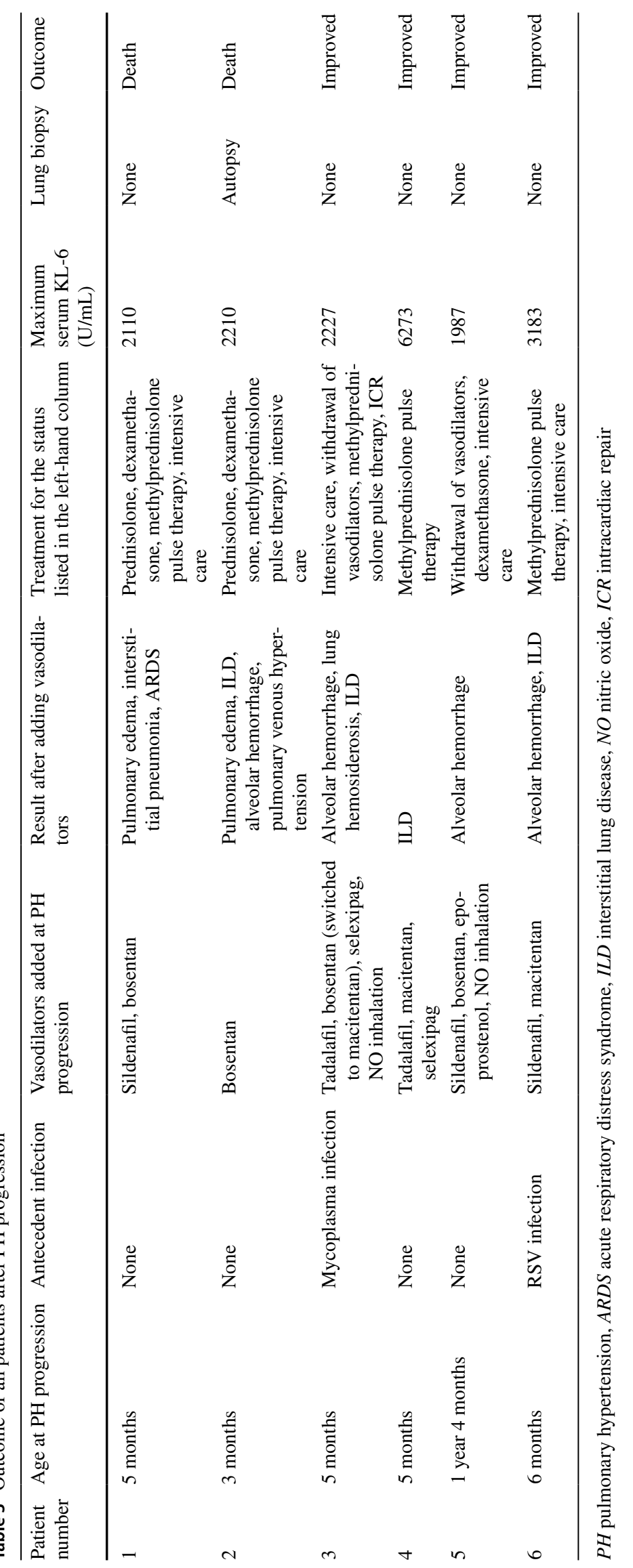




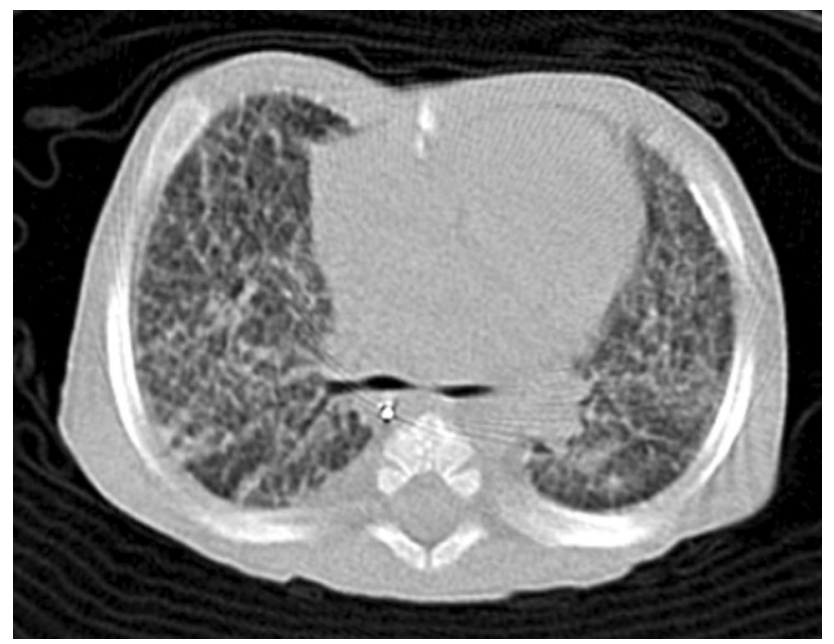

Fig. 1 Chest HRCT scan of patient 2. At 145 days of age, patient 2's lung HRCT image shows panlobular ground-glass opacity and interlobular septal thickening. HRCT high-resolution computed tomography

started selexipag at 168 days of age and NO inhalation at 171 days of age. He often had deep desaturation when sucking phlegm or crying, and the amount of bloody sputum increased from 176 days of age; thus, he was admitted to the intensive-care unit. His bloody sputum increased further despite strict ventilator management and administration of a hemostatic agent and fresh-frozen plasma. At 181 days of age, his serum KL-6 level increased to $2227 \mathrm{U} / \mathrm{mL}$. His chest computed tomography (CT) scan indicated complication with ILD and alveolar hemorrhage
(Fig. 3a). Methylprednisolone pulse therapy was started, but his condition did not improve. A mycoplasma infection was confirmed by the particle agglutination method, and azithromycin was started. Despite these therapies, his bloody sputum continued, and hemosiderin was found in his intratracheal-suctioned phlegm. His second CT scan revealed dilated pulmonary arteries, proximally to distally (Fig. 3b).

We considered that the high flow status was caused by VSD and that pulmonary vasodilators induced alveolar hemorrhage and respiratory failure; accordingly, we stopped the vasodilators gradually and performed PAB at 199 days of age. Postoperatively, the amount of bloody sputum gradually reduced, and the follow-up CT scan showed a dramatic improvement over the previous findings (Fig. 3c). He was successfully extubated at 216 days of age, and steroid therapy was slowly tapered and stopped at 223 days of age. However, at 241 days of age, his respiratory status deteriorated again. Although methylprednisolone therapy was restarted, it did not improve his respiratory failure. The chest X-ray revealed worsening of the ILD, and his serum KL-6 level increased up to $3036 \mathrm{U} / \mathrm{mL}$. To control the pulmonary artery flow, he underwent VSD patch closure at 275 days of age. His respiratory status was dramatically improved postoperatively. At 305 days of age, he was discharged from the hospital with home oxygen therapy, oral prednisolone, and budesonide inhalation therapy.

Figure 4 reveals the chest CT image of the other patients. Patients 1, 4, and 6 (Fig. 4a, b, d) had reference findings of $\mathrm{PVOD} / \mathrm{PCH}$; panlobular ground-glass opacity, interlobular septal thickening, and funicular shadows
Fig. 2 Histopathological findings of the lung autopsy for patient 2 at 181 days of age. a Small pulmonary arteries with a diameter of $50 \mu \mathrm{m}$ have a medial thickness. Yellowish hemosiderin deposition is also found. b Almost $50 \%$ of the pulmonary veins have intimal fibrous thickening. c There are many emphysematous bullae and hemosiderin deposits. d Fibrous thickening of the wall of a pulmonary alveolus is revealed. The central white area is lymphangiectasia
(A)

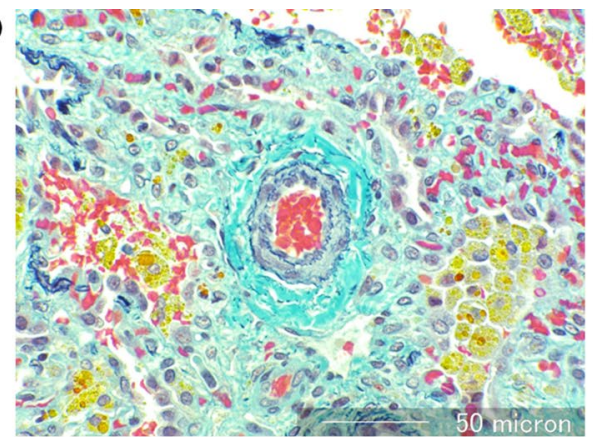

(C)

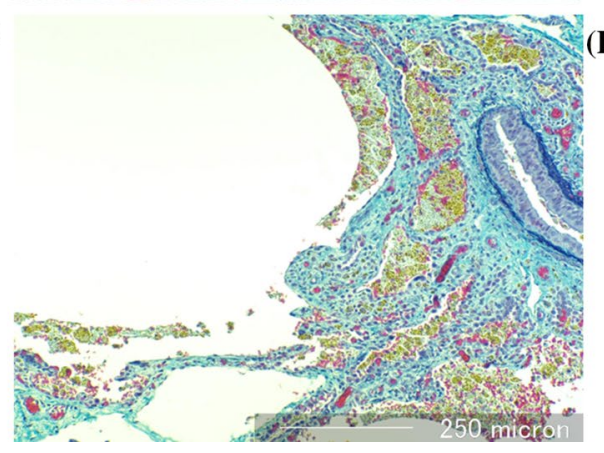

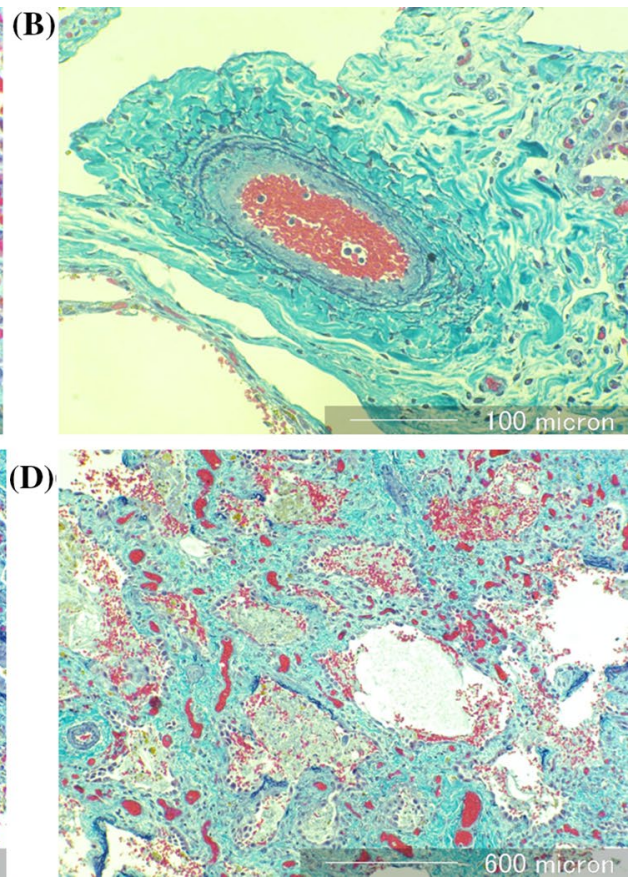



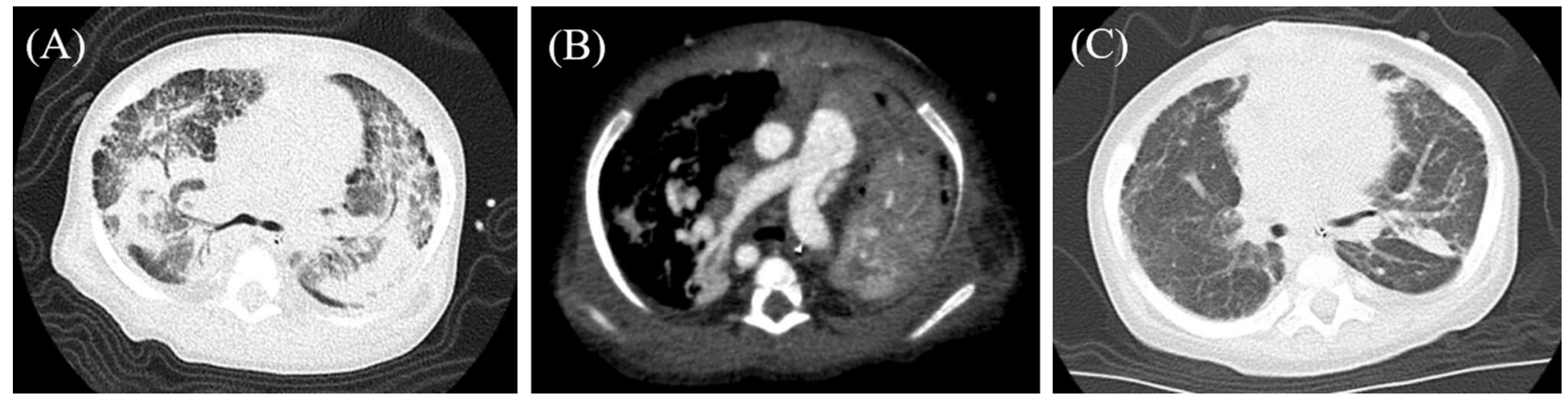

Fig. 3 Chest HRCT scan of patient 3 illustrating fibrosis and alveolar hemorrhage. a At 188 days of age, patient 3's lung HRCT image shows honeycomb cysts involving the subpleural area, alveolar hemorrhage, and parenchymal opacification consisting of consolidation and ground-glass opacities. b At 197 days of age, the HRCT scan revealed dilated pulmonary arteries totally. c At 210 days of age, the follow-up HRCT scan after steroid treatment, cessation of pulmonary vasodilators, and pulmonary artery banding shows marked improvement of the previous findings. HRCT high-resolution computed tomography
Fig. 4 Chest HRCT image of the others. a The HRCT image of patient 1 reveals interlobular septal thickening and interlobar pleura thickening. b The HRCT image of patient 4 shows panlobular ground-glass opacity, mild interlobular septal thickening, and funicular shadows. $\mathbf{c}$ In patient 5 image, only atelectasis and funicular shadows are shown. d Patient 6 image demonstrates ground-glass opacity, interlobular septal thickening, air space consolidation, and atelectasis. HRCT high-resolution computed tomography
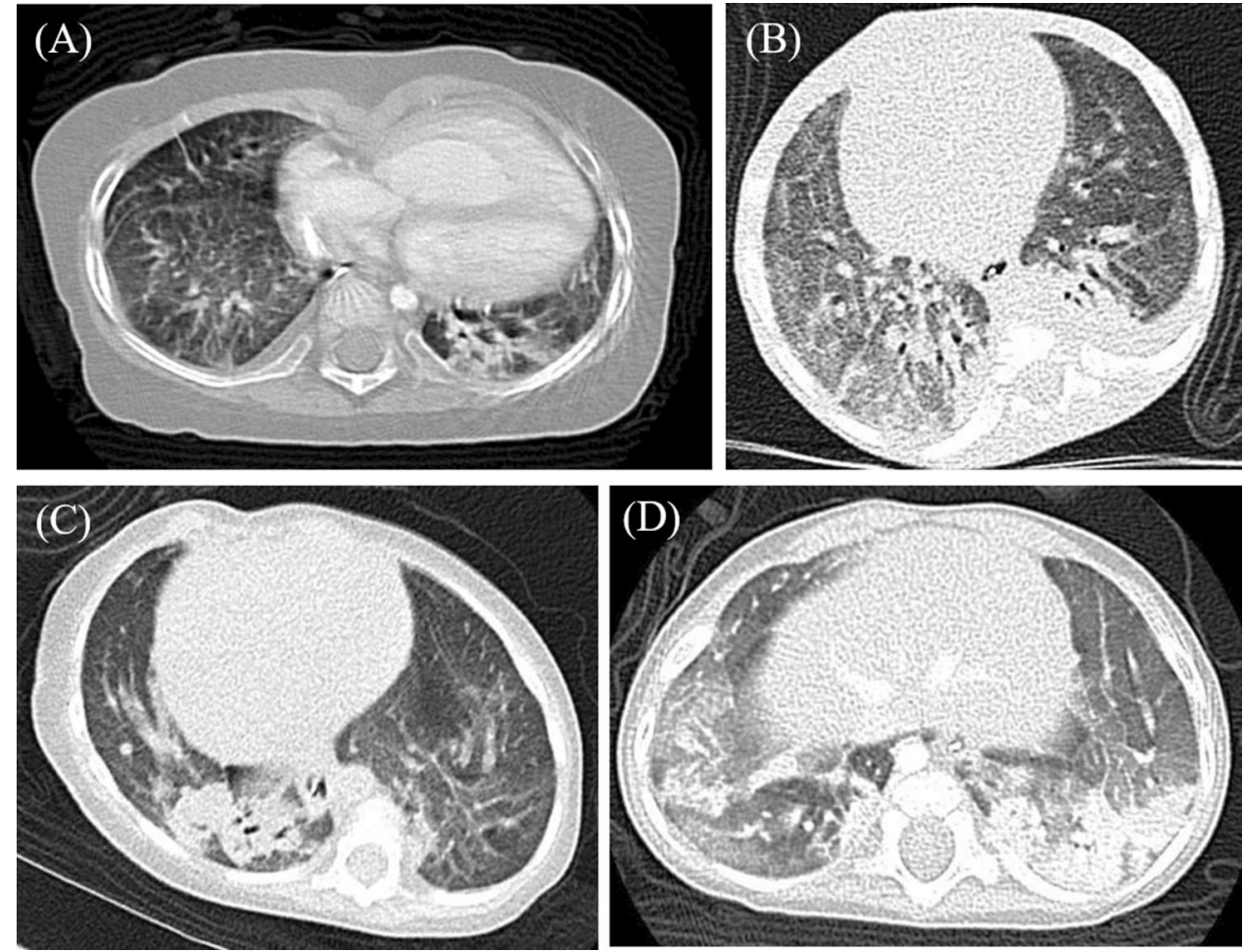

\section{Discussion}

The present study revealed that CHD-PAH could be complicated by PVOD/PCH, ILD, and/or alveolar hemorrhage.

The 6th WSPH statement indicated that decreasing diffusing capacity of the lung for carbon monoxide and severe hypoxia on exercise are useful biomarkers for diagnosing PVOD/PCH. However, it is difficult to assess these biomarkers in children. Although HRCT is also known to be useful for diagnosing $\mathrm{PVOD} / \mathrm{PCH}$, the characteristic findings are not present in all cases of $\mathrm{PVOD} / \mathrm{PCH}$.
In addition, it is challenging to diagnose $\mathrm{PVOD} / \mathrm{PCH}$ in children, because the lung volume is relatively small for HRCT analysis. However, we consider that the HRCT and pathological findings in our cases may indicate the possibility of PVOD/PCH coexistence. Besides, in our CHDPAH cases, we used specific pulmonary vasodilators for deteriorating conditions; their clinical conditions worsened, and they developed pulmonary edema. This phenomenon strongly indicated PVOD/PCH. Muneuchi et al. also reported an infant with CHD-PAH; she died of unexpected deterioration of $\mathrm{PH}$, and lung autopsy proved the existence of PVOD [7]. The frequency of pediatric PAH with 
$\mathrm{PVOD} / \mathrm{PCH}$ is not clear, because there are a few reports, so further investigation is necessary.

In addition to the clinical conditions similar to that reported by Muneuchi et al., our patients were also complicated with alveolar hemorrhage and ILD. To clarify the mechanism, several issues need to be taken into consideration.

1. Complication with congenital malformation syndrome: Trisomy 21 is frequently associated with chronic upper respiratory tract obstruction, sleep apnea syndrome, and hypoxia, caused by infection. These can also be associated with alveolar capillary dysplasia and peripheral lung cysts, and the condition can cause lung dysplasia $[8,9]$. Emphysematous lesions and interstitial lesions can destroy the pulmonary vessels, with deterioration of PH. In addition to trisomy 21 , trisomy 13 ; trisomy 18; DiGeorge syndrome; VACTERL association; and Noonan syndrome also tend to be complicated with CHD-PAH [10, 11]. CHD-PAH in combination with these genetic syndromes can cause deterioration of a patient's clinical condition. However, there are a few reports about CHD-PAH with congenital malformations besides trisomy 21 . Further pathological analysis is necessary.

2. Overlap of pathology with PH: The findings of PVOD/ $\mathrm{PCH}$ can be seen in patients with idiopathic pulmonary fibrosis or combined pulmonary fibrosis and emphysema $[12,13]$. PVOD can also induce fibrosis of lung interstitium [2]. Similar to the relationship between PAH and PVOD/PCH, that between ILD and PVOD/PCH may be less distinct than we think.

3. Relationship between PH and alveolar hemorrhage: It has been reported that hemosiderin-laden macrophages in the sputum of patients with PVOD is found significantly at higher rates compared with the other forms of PH [14]. Lederer et al. argued that engorgement of the capillaries in PVOD leads to occult alveolar hemorrhage. Additionally, pulmonary edema can cause diffuse alveolar hemorrhage, and repetitive alveolar hemorrhages can induce interstitial fibrosis of the lung [15]. Furthermore, pulmonary vasodilators may cause alveolar hemorrhage. It has been revealed that epoprostenol, with anticoagulant therapy, increases one's risk of lung hemorrhage, and sildenafil can induce pulmonary hemorrhage [16-19]. Physicians should be cautious about the risk of alveolar hemorrhage and ILD when treating patients with PAH and PVOD/PCH.

4. Relationship between pulmonary vasodilators and ILD: Several studies have reported that epoprostenol induces ILD [20-22]. Furthermore, the ARTEMIS study was terminated early, because ambrisentan deteriorated the condition of PAH patients with idiopathic pulmonary fibrosis [23]. Moreover, riociguat increased the death rate and deterioration of respiratory status in the RISEIIP trial, which was terminated early [24]. In the 6th WSPH, these 2 aforementioned drugs were determined to be contraindicated for each of these medical statuses [25]. The mechanism of why pulmonary vasodilators can induce or deteriorate ILD is unclear; thus, further investigation is necessary.

Taken together, we illustrate the mechanism of fatal CHD-PAH in Fig. 5. Namely, CHD-PAH, PVOD/PCH, ILD, and alveolar hemorrhage can overlap each other, based on congenital malformation syndrome, respiratory infection, upper airway obstruction, pulmonary vasodilators, and so on. Pulmonary vasodilators can induce pulmonary edema in patients with $\mathrm{PVOD} / \mathrm{PCH}$ and cause deterioration of PVOD/PCH and ILD. Physicians should consider that pediatric patients with severe CHD-PAH may be complicated with congenital malformation syndrome, other forms of $\mathrm{PH}$ caused by PVOD/PCH, or pulmonary disease, and select their treatment carefully. Making a differential diagnosis is sometimes difficult, especially in severe cases. Based on our experience, HRCT and the serum KL-6 level are useful for supporting the diagnosis. The serum KL-6 level is a serum marker for ILD, but it is known to increase in patients with diffuse alveolar hemorrhage. Kida et al. reported that patients with diffuse alveolar hemorrhage whose serum KL-6 level was higher than $700 \mathrm{U} / \mathrm{mL}$ had a significantly poorer prognosis than other patients [26].

In severe cases of CHD-PAH, NO inhalation can be safer than the other oral or intravenous pulmonary vasodilators. Unlike those pulmonary vasodilators, NO does not reach a region with a low-ventilation perfusion ratio and dilate only vessels in a region with a high-ventilation perfusion ratio. It has the advantage of improving general hypoxia. Furthermore, it was reported that in experiments on animals, NO inhalation decreased pulmonary arterial resistance and pulmonary vein resistance [27]. In addition, NO inhalation decreased pulmonary vein resistance and pulmonary capillary pressure in patients with acute respiratory distress syndrome $[28,29]$. These reports suggest that NO inhalation is useful for PVOD/PCH.

When the medical status of patients with CHD-PAH deteriorates even if pulmonary vasodilators are started or the dose is increased, physicians should consider not only the possibility of the limited efficacy of pulmonary vasodilators but also complications of other clinical conditions, such as PVOD/PCH, ILD, and alveolar hemorrhage. The therapeutic strategy of combining multiple pulmonary vasodilators, the so-called combination therapy, is recognized as the standard treatment for adult patients with PAH. Based on the current study, however, careful judgment is needed when choosing combination therapy, 


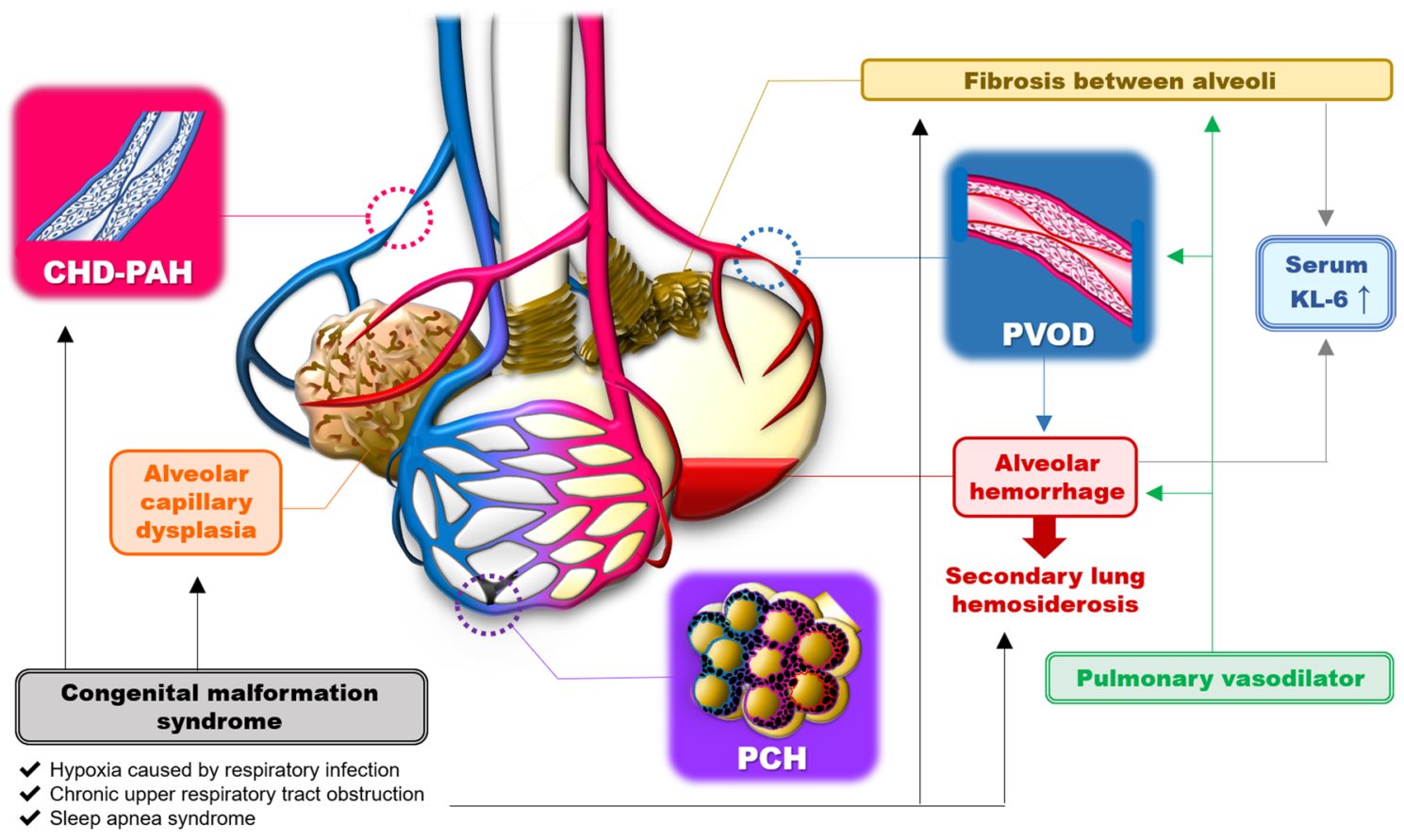

Fig. 5 Estimated mechanism of severe CHD-PAH. CHD-PAH congenital heart disease-associated pulmonary arterial hypertension, $P V O D$ pulmonary veno-occlusive disease, $P C H$ pulmonary capillary hemangiomatosis

especially upfront combination therapy for CHD-PAH, because it may deteriorate the patient's medical status. Further discussion is necessary to determine the proper use of upfront combination therapy for CHD-PAH, and the conclusion should be clearly described in the guideline for managing childhood $\mathrm{PH}$.

In our cases, lung biopsy was not performed to make a definite diagnosis of PVOD/PCH, ILD, and/or alveolar hemorrhage, except in patient 2 who had lung autopsy, and it was difficult to make a definite diagnosis of PVOD/ $\mathrm{PCH}$ and/or other forms of PH. However, lung biopsy is not usually recommended because of the risk of hemorrhage, pneumothorax, and air embolism. Nevertheless, we believe that our clinical inspection policy for our patients was appropriate.

In conclusions, CHD-PAH can occur concomitantly with $\mathrm{PVOD} / \mathrm{PCH}, \mathrm{ILD}$, and/or alveolar hemorrhage. In such a clinical situation, the use of pulmonary vasodilators may be harmful, so we should consider optimal treatments including avoiding combination therapy.

Acknowledgements We are grateful to Dr. Shigeo Yamaki for performing the histopathological examinations. We also thank the medical staffs of Hokkaido University Hospital and Fukuoka Children's Hospital for their assistance in the collection of data.

\section{Compliance with ethical standards}

Conflict of interest Authors have nothing to disclose.

\section{References}

1. Hoeper MM, Bogaard HJ, Condliffe R, Frantz R, Khanna D, Kurzyna M, Langleben D, Manes A, Satoh T, Torres F, Wilkins MR, Badesch DB (2013) Definitions and diagnosis of pulmonary hypertension. J Am Coll Cardiol 62:D42-50

2. Mandel J, Mark EJ, Hales CA (2000) Pulmonary veno-occlusive disease. Am J Respir Crit Care Med 162:1964-1973

3. Wagenvoort CA, Beetstra A, Spijker J (1978) Capillary haemangiomatosis of the lungs. Histopathology 2:401-406

4. Pietra GG, Edwards WD, Kay JM, Rich S, Kernis J, Schloo B, Ayres SM, Bergofsky EH, Brundage BH, Detre KM (1989) Histopathology of primary pulmonary hypertension. A qualitative and quantitative study of pulmonary blood vessels from 58 patients in the National Heart, Lung, and Blood Institute. Prim Pulm Hypertens Regist Circ 80:1198-1206

5. Hadinnapola C, Bleda M, Haimel M, Screaton N, Swift A, Dorfmuller P, Preston SD, Southwood M, Hernandez-Sanchez J, Martin J, Treacy C, Yates K, Bogaard H, Church C, Coghlan G, Condliffe R, Corris PA, Gibbs S, Girerd B, Holden S, Humbert M, Kiely DG, Lawrie A, Machado R, MacKenzie Ross R, Moledina S, Montani D, Newnham M, Peacock A, Pepke-Zaba J, Rayner-Matthews P, Shamardina O, Soubrier F, Southgate L, Suntharalingam J, Toshner M, Trembath R, Vonk Noordegraaf A, Wilkins MR, Wort SJ, Wharton J, Graf S, Morrell NW (2017) Phenotypic characterization of EIF2AK4 mutation carriers in a large cohort of patients diagnosed clinically with pulmonary arterial hypertension. Circulation 136:2022-2033

6. Simonneau G, Montani D, Celermajer DS, Denton CP, Gatzoulis MA, Krowka M, Williams PG, Souza R (2019) Haemodynamic definitions and updated clinical classification of pulmonary hypertension. Eur Respir J 53:1801913 
7. Muneuchi J, Oda S, Shimizu D (2017) Rapidly progressive pulmonary veno-occlusive disease in an infant with Down syndrome. Cardiol Young 27:1402-1405

8. Saji T (2014) Clinical characteristics of pulmonary arterial hypertension associated with Down syndrome. Pediatr Int 56:297-303

9. Bush D, Abman SH, Galambos C (2017) Prominent intrapulmonary bronchopulmonary anastomoses and abnormal lung development in infants and children with Down syndrome. J Pediatr 180:156-162.e151

10. Ma L, Chung WK (2014) The genetic basis of pulmonary arterial hypertension. Hum Genet 133:471-479

11. Tahara M, Shimozono S, Nitta T, Yamaki S (2014) Medial defects of the small pulmonary arteries in fatal pulmonary hypertension in infants with trisomy 13 and trisomy 18 . Am J Med Genet A 164a:319-323

12. Colombat M, Mal H, Groussard O, Capron F, Thabut G, Jebrak G, Brugiere O, Dauriat G, Castier Y, Leseche G, Fournier M (2007) Pulmonary vascular lesions in end-stage idiopathic pulmonary fibrosis: histopathologic study on lung explant specimens and correlations with pulmonary hemodynamics. Hum Pathol 38:60-65

13. Sato T, Tsujino I, Tanino M, Ohira H, Nishimura M (2013) Broad and heterogeneous vasculopathy in pulmonary fibrosis and emphysema with pulmonary hypertension. Respirol Case Rep 1:10-13

14. Lederer H, Muggli B, Speich R, Treder U, Stricker H, Goede J, Ulrich S, Stampfli SF, Breitenstein A (2014) Haemosiderin-laden sputum macrophages for diagnosis in pulmonary veno-occlusive disease. PLoS ONE 9:e115219

15. Ioachimescu OC, Stoller JK (2008) Diffuse alveolar hemorrhage: diagnosing it and finding the cause. Cleve Clin J Med 75:264-265

16. Ogawa A, Matsubara H, Fujio H, Miyaji K, Nakamura K, Morita H, Saito H, Kusano KF, Emori T, Date H, Ohe T (2005) Risk of alveolar hemorrhage in patients with primary pulmonary hypertension-anticoagulation and epoprostenol therapy. Circ J 69:216-220

17. Yuncu G, Ozkurt S, Sinik Z, Kiter G (2006) Hemoptysis developing soon after use of sildenafil: an observation on two cases. Asian J Androl 8:757-758

18. Dixit R, Jakhmola P, Sharma S, Arya M, Parmej AR (2009) Recurrent haemoptysis following sildenafil administration. Indian J Chest Dis Allied Sci 51:119-120

19. Pereira e Silva JL, Araujo Neto CA, Marchiori E (2012) Pulmonary hemorrhage after the use of sildenafil. Heart lung 41:407-408

20. Kudelko KT, Nadeau K, Leung AN, Liu J, Haddad F, Zamanian RT, De Jesus PV (2010) Epoprostenol-associated pneumonitis: diagnostic use of a T-cell proliferation assay. J Heart Lung Transplant 29:1071-1075

21. Morimatsu H, Goto K, Matsusaki T, Katayama H, Matsubara H, Ohe T, Morita K (2004) Rapid development of severe interstitial pneumonia caused by epoprostenol in a patient with primary pulmonary hypertension. Anesth Analg 99:1205-1207

22. Kesten S, Dainauskas J, McLaughlin V, Rich S (1999) Development of nonspecific interstitial pneumonitis associated with long-term treatment of primary pulmonary hypertension with prostacyclin. Chest 116:566-569

23. Raghu G, Behr J, Brown KK, Egan JJ, Kawut SM, Flaherty KR, Martinez FJ, Nathan SD, Wells AU, Collard HR, Costabel U, Richeldi L, de Andrade J, Khalil N, Morrison LD, Lederer DJ, Shao L, Li X, Pedersen PS, Montgomery AB, Chien JW, O'Riordan TG (2013) Treatment of idiopathic pulmonary fibrosis with ambrisentan: a parallel, randomized trial. Ann Intern Med 158:641-649

24. Nathan SD, Behr J, Cottin V, Collard HR, Hoeper MM, Martinez FJ, Wells AU (2017) Idiopathic interstitial pneumonia-associated pulmonary hypertension: a target for therapy? Respir Med 122(Suppl 1):S10-13

25. Nathan SD, Barbera JA, Gaine SP, Harari S, Martinez FJ, Olschewski H, Olsson KM, Peacock AJ, Pepke-Zaba J, Provencher S, Weissmann N, Seeger W (2019) Pulmonary hypertension in chronic lung disease and hypoxia. Eur Respir J 53:1801914

26. Kida Y, Ohshimo S, Ota K, Tamura T, Otani T, Une K, Sadamori T, Iwasaki Y, Bonella F, Hattori N, Hirohashi N, Guzman J, Costabel U, Kohno N, Tanigawa K (2012) KL-6, a Human MUC1 Mucin, as a prognostic marker for diffuse alveolar hemorrhage syndrome. Orphanet J Rare Dis 7:99

27. Ayajiki K, Okamura T, Noda K, Toda N (2002) Functional study on nitroxidergic nerve in isolated dog pulmonary arteries and veins. Jpn J Pharmacol 89:197-200

28. Benzing A, Brautigam P, Geiger K, Loop T, Beyer U, Moser E (1995) Inhaled nitric oxide reduces pulmonary transvascular albumin flux in patients with acute lung injury. Anesthesiology 83:1153-1161

29. Rossetti M, Guenard H, Gabinski C (1996) Effects of nitric oxide inhalation on pulmonary serial vascular resistances in ARDS. Am J Respir Crit Care Med 154:1375-1381

Publisher's Note Springer Nature remains neutral with regard to jurisdictional claims in published maps and institutional affiliations. 